\title{
Assessment of major reproductive health problems, their effect on reproductive performances and association with brucellosis in dairy cows in Bishoftu town, Ethiopia
}

\begin{abstract}
A cross sectional study was conducted in Bishoftu town from November 2015 to May 2016 to investigate major reproductive health problems in dairy cows. From a total of 519 crossbred dairy cows, $30.1 \%(n=156)$ were found to be affected by at least by one reproductive health problems. Hence, retained fetal membrane, repeat breeder, abortion, anestrus and dystocia were found to be the major reproductive health problems containing $10 \%, 8 \%, 8 \%, 7 \%$ and $4 \%$, respectively. Other reproductive health problems observed with lower prevalence include still birth, uterine prolapse, mixed and clinical metritis accounting for $2 \%, 1 \%, 5 \%$ and $1 \%$, respectively. The effect of body condition on the prevalence of major reproductive disorders increased from good to poor body conditioned animals with prevalence of $4.2 \%$ and $13.1 \%$, respectively. On the other hand, the number of parity on the prevalence of major reproductive disorders has a significant $(\mathrm{P}<0.05)$ influence for the occurrence of reproductive problems and the effect increased progressively from pri-miparous to multi-parous with the prevalence of $4 \%$ and $26 \%$ respectively. Furthermore, there was significantly higher $(\mathrm{p}<0.05)$ incidence of retained placenta, repeat breeding and abortion recorded in multiparous than in primiparous cattle. Incidence of overall reproductive problems decreased from heifer to older cows with prevalence of $14.3 \%$ and $0.4 \%$ respectively. Moreover, the production system, hygienic condition of the farms as well as type of insemination did not show a significant variation $(p>0.05)$ for the occurrence of reproductive problems. The overall mean \pm S.D of ages at first service and ages at first calving were $20.3 \pm 5.1$ and $29.4 \pm 5$ months respectively. This study also indicated that the overall mean \pm S.D of calving interval, days open, calving to conception interval and number of services per conception were, $13.4 \pm 2.4$ months and $114 \pm 7,130.2 \pm 71.8$ days, and $1.8 \pm 0.1$ respectively. Two hundred ninety one sera samples were collected and Rose Bengal Plate Test (RBPT) was used as a screening test for brucellosis. RBPT showed that $15(5.2 \%)$ of the tested samples were screened as positive for brucellosis. From 15 RBPT positive sera 12 (4.1\%) were also confirmed to be positive by complement fixation test (CFT). From the total study animals $39(8.7 \%)$ and 52(18.3) were recorded with abortion and retained fetal membrane, respectively. Abortion was found to be significantly associated with sero-positivity of brucellosis in the present study $(\mathrm{p}<0.05)$. This study showed that reproductive disorders highly affected the reproductive performance of dairy cows.
\end{abstract}

Keywords: bishoftu, crossbred dairy cattle, reproductive performance, reproductive problems
Volume 7 Issue I - 2018

\section{Fufa Abunna, Blen Merid, Gebeyehu Goshu, Hika Waktole, Gezahegn Mammo \\ Addis Ababa University, College of Veterinary Medicine and Agriculture, Ethiopia}

Correspondence: Fufa Abunna, Addis Ababa University, College of Veterinary Medicine and Agriculture, P.O. Box 34, Bishoftu, Oromia, Ethiopia, Tel +25I9I I899435,

Email fufa.abunna@aau.edu.et

Received: October 20, 2017 | Published: January 19, 2018
Abbreviations: AAU, addis ababa university; AFC, age at first calving; AFS, age at first service; CFT, complement fixation test; $\mathrm{CI}$ calving interval; CVMA, college of veterinary medicine and agriculture; NSC, number of services per conception; PGF2 $\alpha$, prostaglandin f2 alpha; PPA, post-partum anoestrus; RBPT, rose bengal plate test; $\mathrm{RP}$, retained placenta

\section{Introduction}

Reproductive performance is one key component of dairy production and the goal of reproductive management in dairy cattle is to have cows become pregnant in an efficient manner and at a profitable interval after calving. ${ }^{1}$ So, high reproductive efficiency is necessary for a successful dairy operation and requires a calving interval that maximizes milk production within the herd. ${ }^{2}$ Good estrus detection, good insemination technique, quality semen, and a healthy uterine environment are critical components of high reproductive efficiency. ${ }^{3}$ Infectious diseases have direct impact on reproductive performance of dairy cows. They do have a potential to cause abortion, dystocia, retained placenta, pyometra, metritis, prolapse (uterine and vaginal), anoestrus and repeat breeder. They can be classified as before gestation, during gestation and after gestation., 4 Among the infectious diseases, Brucellosis is highly characterized primarily by causing abortion in late pregnancy, Retained placenta, endometritis and infertility in subsequent pregnancies in cattle. Mature animals are much more susceptible to infection, regardless of sex. In female animals, pregnancy has positive contribution to the degree of susceptibility than their age. ${ }^{6}$ In addition to constraints of low production; it continues to cause heavy economic losses 
and public health concern throughout the world. ${ }^{7}$ In Ethiopia, the differences in management (production) systems and environmental conditions under which cattle are maintained could greatly affect the occurrence of reproductive disorders. ${ }^{8}$ Bishoftu is a potential place which comprises national and international research institutes. Cattle, small ruminant, poultry and equines are the major livestock species kept with fast growing smallholder dairy production. ${ }^{9}$

The livestock population of DebreZeit registered cattle 1,147,173 from this cattle population 513,039 is female cows. ${ }^{10}$ Although, there are enough dairy farms in and around Bishoftu, ample studies have not been conducted on the major reproductive health disorders in dairy animals. ${ }^{11}$ Therefore, the objectives of this study were to investigate major reproductive health problems and their impact on reproductive performance, and to quantify the association between some reproductive disorders and brucellosis positivity in Bishoftu town.

\section{Materials and methods}

\section{Description of the study area}

This study was conducted in Bishoftu town which is located at the distance of $45 \mathrm{~km}$ South East of Addis Ababa, Ethiopia. The town is located in east Showa zone of Oromia region and it lays $9^{\circ}$ North latitude and $40^{\circ}$ East longitude at an altitude of 1850 meters above sea level in the central high land of Ethiopia. It has an annual rainfall of $866 \mathrm{~mm}$ of which $84 \%$ is in the long rainy season (June to September) and the remaining in the short rainy season extending from March to May. The dry season extends from October to February. The mean annual maximum minimum temperatures of the area are $26^{\circ} \mathrm{C}$ and $14^{\circ} \mathrm{C}$ respectively, with mean relatively humidity of $61.3 \%$. Mixed farming system followed in the area, crop and livestock production are an intensive type of production. ${ }^{12}$

\section{Study population and sample size determination}

This study was conducted on dairy cows owned by dairy farmers in Bishoftu town. The majority of dairy producers in the town are market oriented smallholder dairy farmers with average herd size of three cows which are organized under, one dairy cooperative called, Ada'a milk and milk products marketing cooperative share company. There is also few government and private owned large (commercial) scale dairy farms with milking heard size of over 50 in the town. The number of farms sampled for survey studies was determined as follow: ${ }^{13}$
i. $\mathrm{N}=0.25 / \mathrm{SE} 2$,
ii. $\mathrm{N}=$ sample size,
iii. $\mathrm{SE}=\mathrm{Standard}$ error of the population.

A list of 150 farms housing crossbred dairy animals were considered as the sampling frame. Therefore, a total of 100 farms were selected at $5 \%$ standard error with $95 \%$ confidence interval. But, because of unwillingness of some farm owners about 9 farms were excluded from the study. Therefore, the study was conducted by the sample size of 91 dairy farms (61 small holders, 19 medium scales, and 11 large commercial scales) were in this manner selected from the cooperation.

\section{Study design}

The cross-sectional type of study was carried out on reproductive parameters and abnormalities, which was under taken from November
2015 to May 2016. In order to get co-operation of the dairy owners and obtain reliable information about their animals, thorough explanation on the objective of the study was given before the start of the interview. Following that, the actual questions were asked about major reproductive problems on individual cattle level like abortion, Dystocia, still birth, retained fatal membrane, metritis, uterine prolapsed, anestrus, repeat breeding, management systems and parity. Body condition score was based on the criteria adopted by Matthew $\mathrm{MR}^{14}$

a) In BSC 1 (very poor body condition) individual short ribs have a thin covering of flesh,

b) In BCS 2 (poor body condition), individual short ribs can be felt but are not prominent,

c) In BCS 3 (good body condition), ends of short ribs can be felt by applying slight pressure,

d) In BCS 4 (fat), individual short ribs are distinguishable only by firm palpation,

e) In BCS 5 (very fat), bony structures of backbone, short ribs, and hook and pin bones are not apparent.

Subcutaneous fat deposit very evident. Animals were grouped in to those having the major reproductive problems and those without these problems. For the observational study, selection of farms was based on the baseline survey information. A regular visit was carried out once per weeks on 18 dairy farms which was purposively selected on the basis of animal size, facility availability, ease of access and production system. Subsequently, about 73 pregnant cows and 36 heifers that have ages of 2years and above were purposively selected. The study animals were identified by their tag number/ID, parity and pregnant animals that were suspected to give birth within the study period and heifers that has age of 2years and above were included and follow up from the start to the end of study period.

Cows that delivered were observed for the presence of retained fatal membrane left hanging in the vulva in the first $24 \mathrm{~h}$ and if any abnormal vaginal discharge occurred without regular frequency of visit. Sample collection and laboratory tests Blood samples $(5 \mathrm{ml})$ were collected from the jugular vein of each animal, using sterile needles and plain vacationer tubes. The blood samples were allowed to stand overnight at room temperature and centrifuged at $1500 \times \mathrm{g}$ for $10 \mathrm{~min}$. to obtain the serum. Sera were decanted into cryovials, and were stored at $-20^{\circ} \mathrm{C}$ in college of veterinary medicine and agriculture, Addis Ababa University (CVMA, AAU) microbiology laboratory until testing. The Rose Bengal Plate Test (RBPT) was employed as a screening test on the serum samples for the presence of Brucella agglutinins. Positive sera were then retested for confirmation by the complement fixation test (CFT) at the National Animal Health Diagnostic and Investigation Centre (NAHDIC), Sebeta, Ethiopia.

\section{Data management and analysis}

Data generated from questionnaire survey, observational study and laboratory investigations were recorded and coded Using Microsoft Excel spreadsheet (Microsoft Corporation) and analyzed using STATA 13.0 (Stata Corp LP, College Station, TX, USA).

\section{Results}

\section{Major reproductive health problems}

From a total of 519 dairy cows included in the study period 
$30.1 \%(\mathrm{n}=156)$ were found to be affected at least by one reproductive health problems. Overall prevalence of reproductive health problems cited by farmers/attendants or veterinarians in crossbred dairy cattle on different method of study is presented in Table 1. In this study (including questionnaire and observational study) major reproductive health problems were investigated. Hence retained fetal membrane, repeat breeder, abortion, anestrus and dystocia were found to be the major reproductive health problems containing $10 \%, 7.7 \%$, $7.5 \%, 3.7 \%$ and $3.5 \%$, respectively. Other reproductive health problems observed with lower prevalence include still birth, uterine prolapse, mixed and clinical metritis accounting 1.9\%, 0.8\%, 5.2\% and $0.6 \%$ respectively, (Table 2 ). In this study among risk factors; production system, hygienic condition, age, heard size, parity, type of insemination and body condition score were considered to assess its association with the occurrence of the reproductive problems (Table 3 ). The occurrence of overall reproductive problems was significantly affected within the different body condition and parity. The effect of body condition on the prevalence rate of the major reproductive disorders increased from good to poor animals with prevalence of $4.2 \%$ and $13.1 \%$ respectively, (Table 3 ). Generally, body condition had highly significant effect $(\mathrm{P}<0.05)$ on the prevalence of major reproductive disorders. On the other hand, the number of parity on the prevalence rate of major reproductive disorders have a significant $(p<0.05)$ influence for the occurrence of reproductive problems and the effect increased progressively from primiparous to multiparous with prevalence of $3.7 \%$ and $26.2 \%$ respectively. Furthermore, there was significantly higher $(\mathrm{P}<0.05)$ incidence of retained placenta, repeat breeding and abortion was recorded in multiparous than in primi-parous cattle. Incidence of overall reproductive problems decreased from heifer to older cows with prevalence of $14.3 \%$ and $0.4 \%$ respectively. Age was not significantly affected within the different age groups $\left(\mathrm{P}\right.$-value $\left.=0.2291, \mathrm{x}^{2}=1.5\right)$.

Table I Reproductive disorder in dairy cows in Bishoftu town on different method of study

\begin{tabular}{llll}
\hline Method of Study & $\begin{array}{l}\text { Total No. of } \\
\text { observation }\end{array}$ & $\begin{array}{l}\text { No. of cows with } \\
\text { reproductive } \\
\text { disorders }\end{array}$ & $\begin{array}{l}\text { Percent } \\
\text { affected }\end{array}$ \\
\hline $\begin{array}{l}\text { Questionnaire } \\
\text { survey }\end{array}$ & 410 & 137 & $26.50 \%$ \\
$\begin{array}{l}\text { Observational } \\
\text { study }\end{array}$ & 109 & 19 & $3.70 \%$ \\
Total & 519 & 156 & $30.10 \%$ \\
\hline
\end{tabular}

Moreover, the production system, Hygienic condition of the farms as well as type of insemination did not show a significant variation $(\mathrm{P}>0.05)$ for the occurrence of reproductive problems. However, reproductive problems were more prevalent in large scale farm. The results on the overall means of the reproductive performance of dairy cows in the study area, including ages at first service (AFS), ages at first calving (AFC), calving interval (CI), and days open (DO); number of services per conception (NSPC), and calving to conception interval (CCI) are presented in Tables $3 \& 4$. The data indicated that the overall mean \pm S.D of ages at first service and ages at first calving were $20.3 \pm 5.1$ and $29.4 \pm 5$ months respectively. Variables such as body condition score and age has no statistical significant influence on age at first service and age at first calving. The data indicated that the overall mean \pm S.D of calving interval, days open, calving to conception interval and number of services per conception were, $13.42 \pm 2.4$ months and $113.9 \pm 66,130.2 \pm 71.8$ days, and $1.8 \pm 0.1$ respectively. According to the present research finding variables such as age and body condition score has statistical significant influence $\mathrm{p}<0.05$ on days open and number of service preconception. Old age cows had longer calving interval and days open than others. Besides, those who have poor body condition score have longer number of service preconception than from that of medium and good once (Table 4).

Table 2 Relative occurrence of major reproductive disorders in dairy cows in Bishoftu town

\begin{tabular}{llll}
\hline Types of Rds & $\begin{array}{l}\text { Questionnaire } \\
\text { survey No(\%) }\end{array}$ & $\begin{array}{l}\text { Regular follow } \\
\text { up No(\%) }\end{array}$ & Total(\%) \\
\hline RFM & $48(11.7 \%)$ & $4(3.7 \%)$ & $52(10 \%)$ \\
Repeat breeding & $33(8.04 \%)$ & $7(6.4 \%)$ & $40(7.7 \%)$ \\
Abortion & $34(8.3 \%)$ & $5(4.6 \%)$ & $39(7.5 \%)$ \\
Anoestrus & $17(4.1 \%)$ & $2(1.8 \%)$ & $19(3.7 \%)$ \\
Dystocia & $17(4.1 \%)$ & $1(0.9 \%)$ & $18(3.5 \%)$ \\
Still birth & $10(2.4 \%)$ & $0(0 \%)$ & $10(1.9 \%)$ \\
$\begin{array}{l}\text { Uterine } \\
\text { prolapse }\end{array}$ & $4(1 \%)$ & $0(0 \%)$ & $4(0.8 \%)$ \\
Clinical metritis & $3(0.7 \%)$ & $0(0 \%)$ & $3(0.6 \%)$ \\
Mixed disorder & $26(96.3 \%)$ & $\mathrm{I}(3.7 \%)$ & $27(5.2 \%)$ \\
\hline
\end{tabular}

*Mixed problems include abortion and retained placenta, anestrus and repeat breeding, and dystocia and retained placenta, repeat breeding, abortion and retained placenta repeat breeding, uterine prolapse, retained placenta, and clinical metritis, ( 2 and above cases)

Each performance trait measured was adversely affected by reproductive abnormalities of cows. Abnormal cows had longer days open, calving to conception interval and required more service per conception that normal cows $(\mathrm{P}<0.05)$. Therefore, calving interval were longer in cows with reproductive abnormalities $(\mathrm{P}<0.05)$. Overall, the interaction between reproductive health status of cows and performance trait was significant. Among 291 tested samples, $15(5.2 \%)$ were found positive by RBPT and $12(4.1 \%)$ were found positive by CFT. Therefore, in the present study, an overall seroprevalence was estimated to be $4.1 \%$ by CFT. In the present study, abortion, repeat breeder and retained fetal membrane were observed as some major reproductive health problems with the prevalence of $10 \%$, $7.7 \%$ and $7.5 \%$ respectively. Out of 39 female animals in the study area with abortion history $4(10.2 \%)$ of them were detected positive for brucellosis. In addition, out of 52 retained fetal membranes $2(3.8 \%)$ of them were positive for brucellosis. However, out of 40 repeat breeder history all of them were negative for brucellosis. A history of previous abortions had been significantly related to seropositive of brucellosis. But a history of previous retain fetal membrane had not been significantly related to seropositive of brucellosis. Using univariate logistic regression odds ratio was calculated to measure the likely association that could exist between brucellosis and abortion as well as retained fetal membrane. From both cases abortion was strongly associated with brucellosis with values of odds ratio 6.8 
(Table 5). On the other hand, there was statistically significant association $(\mathrm{P}<0.05)$ between abortion period and sero positivity of brucellosis with values of odds ratio 2.1. This could be explained by the presence of higher sero-positivity in cows in the last trimester may be due to the preferential localization of Brucella in the uterus in which allantoic fluid factors such as erythritol could stimulate the growth of Brucella and elevate in the placenta and fetal fluid from about the 5 th month of gestation.

Table 3 Influence of different risk factors on major reproductive problems in the study area

\begin{tabular}{lllllll}
\hline Variables & AFS $(\mathbf{m})$ & \multicolumn{5}{c}{ AFC $(\mathbf{m})$} \\
\hline BCS & No & Mean \pm SD & P-value & No & Mean \pm SD & P-value \\
Poor & 122 & $19.4 \pm 0.5$ & 0.544 & 122 & $28.8 \pm 0.4$ & \\
Medium & 306 & $20.5 \pm 0.3$ & & 304 & $29.6 \pm 0.3$ & 0.464 \\
Good & 91 & $19.9 \pm 0.5$ & & 91 & $29.2 \pm 0.5$ & \\
Age & & & & & & \\
2-4years & 276 & $20.4 \pm 0.3$ & 0.73 & 274 & $29.5 \pm 0.3$ & \\
5-8years & 231 & $19.8 \pm 0.8$ & & 231 & $29.1 \pm 0.3$ & 0.181 \\
$>8$ years & 12 & $20.9 \pm 1.7$ & & 12 & $31.1 \pm 1.9$ & \\
Overall & $20.27 \pm 5$ & & & $29.38 \pm 5$ & &
\end{tabular}

Table 4 Calving interval, days open, number of services per conception and calving to conception interval of dairy cows in the study area

\begin{tabular}{|c|c|c|c|c|c|c|c|c|c|c|c|c|}
\hline \multirow[t]{2}{*}{ Variables } & \multicolumn{3}{|c|}{$\mathrm{Cl}(\mathrm{m})$} & \multicolumn{3}{|c|}{$\mathrm{DO}(\mathrm{d})$} & \multicolumn{3}{|c|}{ NSC } & \multicolumn{3}{|c|}{$\mathrm{CCl}(\mathrm{d})$} \\
\hline & No & Mean $\pm s d$ & p-value & No & Mean \pm sd & p-value & No & Mean \pm sd & p-value & No & Mean士sd & p-value \\
\hline \multicolumn{13}{|l|}{ Parity } \\
\hline Primiparous & - & - & & 9 & - & & 36 & - & & 7 & - & \\
\hline Multiparous & 483 & $|3.36 \pm 2.4|$ & & 483 & $113.61 \pm 66.5$ & - & 483 & $1.78 \pm 0.08$ & - & 483 & $129.83 \pm 72.39$ & - \\
\hline \multicolumn{13}{|l|}{ BCS } \\
\hline Poor & 117 & $13.84 \pm 2.53$ & $0.07 I$ & 118 & $116.82 \pm 59.15$ & 0.935 & 122 & $2.3 \pm 1.12$ & 0 & 117 & $144.56 \pm 75.40$ & 0.055 \\
\hline Medium & 281 & $13.27 \pm 2.6$ & & 288 & II $5.33 \pm 75.88$ & & 306 & $1.56 \pm 0.82$ & & 287 & $127.14 \pm 77.65$ & \\
\hline Good & 85 & $13.02 \pm 1.23$ & & 86 & $106.04 \pm 30.42$ & & 91 & $1.69 \pm 0.86$ & & 86 & $120.94 \pm 38.07$ & \\
\hline \multicolumn{13}{|l|}{ Age } \\
\hline 2-4years & 240 & $13.14 \pm 1.95$ & 0.006 & 249 & $109.78 \pm 57.17$ & 0.002 & 276 & $1.64 \pm 0.95$ & 0.076 & 247 & $|23.6| \pm 5.7 \mid$ & 0.174 \\
\hline 5-8years & 231 & $13.55 \pm 2.6$ & & 231 & II $7.38 \pm 70.34$ & & 231 & $1.9 \pm 0.18$ & & 231 & $|35.80 \pm 77.9|$ & \\
\hline$>8$ years & 12 & $14.33 \pm 5.36$ & & 12 & $142.5 \pm \mid 28.63$ & & 12 & $1.75 \pm 0.48$ & & 12 & $158.25 \pm 156.63$ & \\
\hline Overall & & $13.42 \pm 2.40$ & & & $1|3.90 \pm 66.0|$ & & & $1.75 \pm 0.07$ & & & $|30.17 \pm 7| .83$ & \\
\hline
\end{tabular}

M, month; $\mathrm{D}$, day; $\mathrm{Cl}$, calving interval; $\mathrm{DO}$, days open; NSC, number of service preconception; $\mathrm{CCl}$, calving to conception interval

Table 5 Association of RFM and abortion with brucellosis positivity

\begin{tabular}{llllll}
\hline Clinical signs & $\mathbf{N}$ & Prevalence(N) & Confidence interval & OR & P-value \\
\hline \multicolumn{2}{l}{ Retain fetal membrane } & & & & \\
Yes & $52(10 \%)$ & & & & \\
No & $467(90 \%)$ & $3.8 \%(2)$ & $0.4-8.6$ & 1.828 & 0.444 \\
Abortion & & & & \\
Yes & $39(7.5 \%)$ & & & 6.74 & $0.003 * *$ \\
No & $480(92.5 \%)$ & & $1.9-23.5$ & & \\
\hline
\end{tabular}


Table Continued..

\begin{tabular}{llllll}
\hline Clinical signs & $\mathbf{N}$ & Prevalence(N) & Confidence interval & OR & P-value \\
\hline Abortion period & & & & \\
First trimester & $8(1.5 \%)$ & $0(0)$ & & \\
Second trimester & $18(3.5 \%)$ & $0(0)$ & $1.6-4.172 .6$ & $0.000^{* *}$ \\
Not applicable & $480(92.5 \%)$ & $0(0)$ & & \\
Third trimester & $13(2.5 \%)$ & $30.7 \%(4)$ & & \\
\hline
\end{tabular}

$\mathrm{N}$, number of observations; $\mathrm{OR}=$ odds ratio

\section{Discussion}

In the present study around $30 \%$ of dairy cattle were affected by either one or more reproductive disorders. This rate is in the range of 18 to $45 \%$ previously described for this kind of pathology in Ethiopia. ${ }^{15-19}$ Variations in prevalence may be due to sample size, study methodology, environmental factors, breeds of the animals and variation in management system that is applied in different dairy farms. Retained fetal membrane was found to be $10 \%$, fairly agrees with $11.5 \%$ reported by Alemselam B et al. ${ }^{20}$ but lower than $14.7 \%$ reported by Haile A et al. ${ }^{21}$ and $19.2 \%$ by Gashaw A. ${ }^{22}$ Cows which gave more birth were susceptible to dystocia. Inseminating cows with semen collected from large sized bulls without taking into account the size and age of cows is an important factor in precipitating dystocia..$^{12,23}$ According to Esheti $\mathrm{G}^{24}$ dystocia primary occurs among first calf heifers as a result of feto-pelvic disproportion i.e., because of calf size or pelvic dimension of dam. The prevalence of repeated breeding revealed $7.7 \%$ which agree with the finding of ${ }^{24}$ who reported $7.3 \%$ in crossbred cows/heifers. Moreover, the incidence of repeat breeding is comparatively lower than the $13.1 \%$ and $21 \%$ reported by Adane $\mathrm{H}^{15}$ Alemselam B et al. ${ }^{20}$ respectively. High incidence of repeat breeding could be due to lack of nutrition, improper insemination and timing of $\mathrm{AI}$ and poor semen quality. ${ }^{25}$ Abortion was $7.5 \%$ which is a bit greater than the findings of ${ }^{17} 6.7 \%$ in Central Ethiopia. But, lower than $9.1 \%$, $13.9 \%$ and $14.6 \%$ reported by Hunduma $\mathrm{D},{ }^{18}$ Molalegne $\mathrm{B},{ }^{19}$ Dawite and Ahmed ${ }^{26}$ respectively. The variation could be due to metabolic or hormonal abnormalities, nutritional deficiencies, trauma, toxicities, or infectious agents. ${ }^{27,28}$

Stillbirth was occurring at the rate of $1.9 \%$ which is bit less than the findings of ${ }^{21} 2.8 \%$ in Addis Ababa milk shed. But, higher than 3\% reported by Dawite and Ahmed ${ }^{26}$ Still births can occur due to forceful fetal extraction, hypocalcaemia and various pathogens. Multipara cows were more affected by reproductive disorders than the primipara as has also reported earlier by Dawite and Ahmed ${ }^{26}$ in Kombolcha and Adane $\mathrm{H}^{15}$ Hosanna. Uterine involution was significantly delayed as the parity increases and thereby the interval from calving to ovarian resumption was also prolonged. ${ }^{29}$ Furthermore, an increase in parity not only brings reproductive problems but can also lead to serious locomotive, mammary and metabolic disorders. ${ }^{30} \mathrm{BCS}$ significantly influenced the occurrence of reproductive diseases in crossbred dairy cows, lowest in medium BCS and highest in low BCS also reported by Getachew E. ${ }^{11}$ The means \pm SD (10months to 37months) age at first (AFS) serviced were 20.1 \pm 4.7 . This was lower than the report of $^{31} 32.1 \pm 0.6$ months. A higher AFS also been reported than the current finding 27.5 months and 24.3 months respectively. ${ }^{32}$ This could be because of low level of management and poor feeding of calves and heifers at the earlier stages, which consequently had reduced growth rate and delayed puberty. The means $\pm \mathrm{SD}$ (19months to 52 months) of AFS were $29.4 \pm 4.8$ months in Bishoftu town. In the present study, the average AFS was lower than AFC of $41.2 \pm 0.6$ months, which is reported by Belay D. ${ }^{32}$

Moreover, the mean result of AFS in the present study was lower than that of ${ }^{18,33,34} 34.8 \pm 4,32.4$ and $36.4 \pm 17$ months, respectively. The high AFS observed here may be related to environmental conditions and husbandry practices which may effect on the cattle growth. Days open (DO) was $114.1 \pm 66.1$ days which is longer than the findings of ${ }^{18}$ 85.6 days and ${ }^{35} 93.1$ days. This might be due to differences in breeding management, health care and attributed to inadequate nutrition particularly energy supply through the concentrates. The major nutritional factor decreasing reproductive efficiency of high yielding dairy cows resulted by negative energy balance that induces a delay in first ovulation after calving (or a low oocyte quality) and increase in embryo mortality incidence with interval from calving to conception that increases over 120-130days. ${ }^{4}$ The reproductive performance of cattle, particularly the probability of conception, may be negatively associated with the magnitude and duration of negative energy balance in early lactation. ${ }^{36}$ The overall mean value for the number of services preconception (NSC) was 1.8 which is in agreement with the results of $(1.7 \pm 0.1){ }^{37}$ However, higher than ${ }^{33}(1.3 \pm 0.6)$ and $^{38}$ (1.5 \pm 0.9$)$. Two and more number service per conception might be due to lack of semen quality, insufficient nutrition, reproductive disorder, use of improper inseminating techniques, the presence of repeat breeders in the herd and problems of heat detection. The mean CCI was $130.2 \pm 72.1$ days. It is lower than ${ }^{39} 257$ days. The differences may be attributed to management problems such as nutrition and breeding practice.

Inadequate nutrition interferes with the resumption of ovarian activity and CCI by impairing the release of luteinizing hormone which consequently delays the occurrence of ovulation..$^{40}$ The overall sero-prevalence of bovine brucellosis was $4.1 \%$, which is agreed with $3.1 \%$ and $4.3 \%$ reported by Ibrahim $\mathrm{N}^{41}$ and Tibesso $\mathrm{G}^{42}$ respectively. But lower than ${ }^{43} 8 \%$ and $^{38} 11.2 \%$. The incidence of brucellosis to abortion was $10.2 \%$ which is higher $\operatorname{than}^{44} 8.7 \%$, however, lower than ${ }^{45} 12 \%$. This difference in prevalence rate may be due to sample size, study methodology and variation in cattle husbandry management system. There was statistically significant association $(<0.05)$ between abortion period and sero-positivity of brucellosis. This could be explained by the presence of higher sero-positivity in cows in the last trimester may be due to the preferential localization of Brucella in the uterus in which allantoic fluid factors such as erythritol could stimulate the growth of Brucella and elevate in the placenta and fetal fluid from about the 5 th month of gestation. ${ }^{46,47}$

\section{Conclusion}

Body condition, parity and high prevalence of abortion and retained 
placenta together with high incidence of brucellosis were the possible risk factors for major causes of low reproductive performances of dairy cowsin Bishoftu town, Ethiopia.

\section{Acknowledgements}

The study was conducted with the help of field assistants. We would like to thank the dairy farm owners for their willingness to cooperate. Fieldwork was sponsored by Addis Ababa university research directorate.

\section{Conflict of interest}

Authors declare there is any conflict of interest.

\section{References}

1. Plaizier JC, King GJ, Dekkers JC, et al. Estimation of economic values of indices for reproductive performance in dairy herds using computer simulation. J Dairy Sci. 1997;80(11):2775-2783.

2. Ferguson J, Galligan D. Assessment of reproductive efficiency in dairy herds. Compend Contin Ed Prac Vet. 2000;22:159-158.

3. Nebel R. Optimizing fertility in the dairy herd. In: Proceedings of the annual conference of Society of Theriogenology. USA; 1999. p. 443-452.

4. Lobago F, Bekana M, Gustafsson H, et al. Reproductive performances of dairy cows in smallholder production system in Selalle, Central Ethiopia. Trop Anim Health Prod. 2006;38(4):333-342.

5. Shiferaw Y, Tenhagen B, Bekana M, et al. Reproductive disorders of crossbred dairy cows in the central highlands of Ethiopia and their effect on reproductive performance. Trop Anim Health Prod. 2005;37(5):427-441.

6. Rossi F, Righi F, Romanelli S, et al. Reproductive efficiency of dairy cows under negative energy balance conditions. Ann Fac Medic Vet di Parma. 2008;28:173-180.

7. OIE. Bovine Brucellosis. Manual of standards for diagnostic tests and vaccine. Office Int Des Epizooties. Paris; 2003.

8. Seifert S. Tropical animal Health. The Netherlands: Kluwer Academic Publishers; 1996. p. 356-367.

9. IPMS: Improving Productivity and Market Success. Dale thematic maps. IPMS, Ethiopia; 2005.

10. CSA: Central Statistical Agency. Report on livestock and livestock characteristics. The Federal Democratic republic of Ethiopia, Private Peasan Holdings. Statistical Bulletin. Ethiopia; 2015.

11. Getachew E, Nibret M. Major Reproductive Health Disorders in Cross Breed Dairy Cows in Ada'a District, East Shoa, and Ethiopia. Glob Vet. 2014;13(4):444-449.

12. Noakes DE. Fertility and Obstetrics in cattle. Oxford: Black well, Sci. Pub; 1986:28-30.

13. Arsham H. Questionnaire design and surveys sampling. 9th ed. 2007.

14. Matthew MR. Dairying Centre for tropical veterinary medicine. UK: University of Edinburgh, Mc Millan press Ltd; 1993:67-68.

15. Adane H, Yisehak T, Niguse T. Assessment of Major Reproductive Disorders of Dairy Cattle in Urban and Per Urban Area of Hosanna, Southern Ethiopia. Anml Vet Sci. 2014;2(5):135-141.

16. Gizaw Y, Bekana M, Abayneh T. Major reproductive health problem in small holder dairy production in and around Nazareth Town. Central Ethiopia, Addis Ababa University, Faculty of Veterinary Medicine, DVM thesis, Bishoftu Ethiopia; 2011.
17. Hadus A, Abdella A, Ragassa F. Major Prepartu and postpartum Reproductive problems of dairy cattle in central Ethiopia. $J$ Vet Med Anim Health. 2013;5(4):118-123.

18. Hunduma D. Reproductive performance of crossbred dairy cows under smallholder condition in Ethiopia. Int $J$ Livest Res Rural Dev. 2012;3(3):25-28.

19. Molalegne B, Shiv P. Study on Major Reproductive Health Problems in Indigenous and Cross Breed Cows in and Around Bedelle, South West Ethiopia. J Anim Vet Adv. 2011;10(6):723-727.

20. Alemselam B, Christopher R, Simon C, et al. Assessment of Reproductive Performance and Problems in Crossbred (Holstein Friesian X Zebu) Dairy Cattle in and Around Mekelle, Ethiopia. Anm Vet Sci. 2015;3(3):94-101

21. Haile A, Kassa T, Mihret M, et al. Major reproductive disorders in cross breed dairy cow under smallholding in Addis Ababa milk shed. WJ Agri Sci. 2010;6(4):412-418.

22. Gashaw A, Worku F Mulugeta S. Assessment of small holder dairy production system and their reproductive health problems in Jimma town South Weast Ethiopia. Int J App Res. 2011;9(1):80-86.

23. Anderson L, Gustafson H, Emanuelson U. Effect of hyper-ketonemia and feeding on fertility in dairy cows. Theriogenology. 1996;36:521-536.

24. Esheti G, MogesN. Major Reproductive Health Disorders in Cross Breed Dairy Cows in Ada'a District, East Shoa, Ethiopia. Glo Vet. 2014;13(4):444-449.

25. Mandefro M, Negash G. Repeat Breeder Syndrome in Dairy Cows Influence of Breed and Age on Its Prevalence. World J Agric Sci. 2014;10(4):200-203.

26. Dawit T, Ahmed S. Reproductive Health Problems of Cows under Different Management Systems in Kombolcha, Northeast Ethiopia. Advan Biol Res. 2013;7(3):104-108.

27. Givens MD. A clinical, evidence-based approach to infectious causes of infertility in beef cattle. Theriogenology. 2006;66(3):648-654.

28. Ortega-Mora M, Gottstein B, Conraths F, et al. Protozoal abortion in farm ruminants: guidelines for diagnosis and control. UK: CAB International; 2007.

29. Erb H, Martin S. Interrelationship between production and reproductive disease in Holstein cows. Data. J Dairy Sci. 1980;63:1911-1917.

30. Bonneville-Hébert A, Bouchard E, Tremblay DD, et al. Effects of reproductive disorder and parity on repeat breeder status and culling of dairy cows. Can J Vet Res. 2011;75(2):147-151.

31. Yifat D, Kelay B, Bekana M, et al. Study on reproductive performance of crossbred dairy cattle under smallholder conditions in and around Zeway, Ethiopia. Livestock Res Rural Dev. 2009;9(6):21.

32. Belay D, Yisehak K, Janssens G. Productive and reproductive performance of Zebu X Holstein-Friesian crossbred dairy cows in Jimma town, Oromia, Ethiopia. Glob Vet. 2012;8(1):67-72.

33. Nibret M. Study on reproductive performance of crossbred dairy cows under small holder conditions in and around Gondar, North Western Ethiopia. J Reprod Infertil. 2012;3(3):38-41.

34. Kumar N, Yemane A, Berihu G, et al. Production performance of dairy cows under farmer's management in and around Mekelle, Ethiopia. Glob Vet. 2014;12(2):207-212.

35. Niraj K, Alemayehu E, Abreha T, et al. Productive performance of indigenous and Holstein-Friesian crossbred dairy cows in Gondar, Ethiopia. Vet World. 2014;7(3):177-181. 
36. Walsh SW, Williams EJ, Evans AC. A review of the causes of poor fertility in high milk producing dairy cows. Anim Reprod Sci. 2011;123:127-138

37. Gebeyehu G, Kelay B, Abebe B. Effect of parity, season and year on reproductive performance and herd life of Friesian cows at Asella private dairy farm, Ethiopia. Livestock Res Rural Dev. 2007;19(7).

38. Hunduma D, Regassa C. Sero-prevalence study of bovine brucellosis in pastoral and agro-pastoral areas of East Showa zone, Oromia Regional State, Ethiopia. Amer. Eurasian J Agri Environ Sci. 2009;6(5):508-512.

39. Ali T, Lemma A, Yilma T. Reproductive performance of dairy cows under artificial insemination in south and northwest part of Ethiopia. Livestock Res Rural Dev. 2013;25:191.

40. Bolaños JM, Meneses A, Forsberg M. Resumption of ovarian activity in Zebu cows (Bosindicus) in the humid tropics: influence of body condition and levels of certain blood components relayed to nutrition. Trop Anim Health Prod. 1996;28(3):237-246.

41. Ibrahim N, Belihu K, Lobago F, et al. Sero-prevalence of bovine brucellosis and its risk factors in Jimma zone of Oromia Region, South-western Ethiopia. Trop Anim Health Prod. 2010;42(1):34-40.
42. Tibesso G, Ibrahim N, Tolosa T. Sero prevalence of bovine and human brucellosis in Adami Tulu, Central Ethiopia. World Appl Sci J. 2014;31(5):776-780.

43. Megersa B, Biffa D, Abunna F, et al. Sero epidemiological study of livestock brucellosis in a pastoral region. Epidemiol Infect. 2012;140(5):887-896

44. Teferi D, Asmamaw D, Reta D. Brucellosis and Some Reproductive Problems of Indigenous Arsi Cattle in Selected Arsi Zone of Oromia Regional State, Ethiopia. Glob Vet. 2011;7(1):45-53

45. Amene F. Studies on reproductive performance and major reproductive health problems of HF cows at Alage dairy farm. Bishoftu, Ethiopia: MSc thesis, Addis Ababa University, Faculty of Veterinary Medicine; 2006 .

46. Coetzer J, Tustin R. Infectious diseases of livestock. 2nd ed. USA: South Africa Oxford University press; 2004:34-39.

47. Radostits O, Gay C, Hinchcliff W, et al. Veterinary Medicine. A Text book of Diseases of Cattle, Sheep, Pigs, Goats and Horses. 10th ed. UK: W.B Saunders; 2007. p. 963-985. 